\title{
Tunable growth of single-wall CNTs by monitoring temperature increasing rate
}

\author{
Nishant Tripathi ${ }^{1,2} \cdot$ Vladimir Pavelyev $^{2} \cdot$ S. S. Islam ${ }^{1}$
}

Received: 22 January 2018 / Accepted: 6 May 2018 / Published online: 15 May 2018

(c) The Author(s) 2018

\begin{abstract}
We report here new aspects of CNT growth by CVD system where temperature increasing rate plays a key role in controlling the diameter, structural quality, and yield of CNTs. Temperature increasing rates were used in the range $100-600{ }^{\circ} \mathrm{C} / \mathrm{h}$ and growth morphology was constantly monitored at every step by HRTEM, FESEM and Raman spectroscopy. Morphology as well as structural quality of CNTs is sharply enhanced with the increase in temperature increasing rate, and it is found that the onset of SWNTs growth starts at $600{ }^{\circ} \mathrm{C} / \mathrm{h}$. In this work, we also proposed that the diameter of grown CNTs is independent from the size of catalyst particles used for initiation of CNTs growth unlike the conventional concept in the field of CNTs growth.
\end{abstract}

Keywords Controlled growth $\cdot$ SWNTs $\cdot$ Temperature increasing rate $\cdot$ CVD

\section{Introduction}

Since the discovery of CNTs in 1990, researchers worldwide have been working on the synthesis of various nanomaterials with an aim for its perfection and in-depth understanding of the synthesis [1-3]. Although many applications based on CNTs have been made and many more in the process [4-7], repeatability and selectivity in CNTs growth create a huge obstacle in the way of industrialization of CNTsbased applications; all these are due to the lack of stabilization of growth as well as understanding in CNTs growth mechanism.

There are so many techniques available for CNTs growth [8]. But CVD has a wide range of growth parameters to tune the CNTs structure and, therefore, CVD is the most preferred technique for CNTs growth. Literature survey shows that researchers have already reported the role of various growth parameters like flow rate and flow duration of hydrocarbon $[9,10]$, flow rate of Argon [11], growth temperature [12,

S. S. Islam

sislam@jmi.ac.in

1 Centre for Nanoscience and Nanotechnology, Jamia Millia Islamia (A Central University), Jamia Nagar, New Delhi 110025, India

2 Department of Nanoengineering, Samara National Research University, 34, Moskovskoye shosse, Samara 443086, Russia
13] and different type of catalyst [14, 15] on the structure of grown CNTs. However, in addition to these parameters, temperature increasing rate of CVD system is another important parameter to be looked upon in CNTs growth which is not so far reported. Temperature increasing rate affects the catalyst engineering, i.e., control on breaking of sputtered thin transition metal film into nanosized catalysts particle as well as its molecular structure.

The catalyst particles play a very important role in CNTs growth and a detailed analysis is needed to understand their role mechanism. It was reported by some research groups that the size of catalyst is the decisive factor in controlling the size of the diameter and number of walls in grown CNTs [16]. Some reported works highlighted that diameter of catalyst particle is always much greater than the diameter of grown CNTs [17]. Not only that, there are reports where one catalyst particle even produces more than one CNTs [18]. These studies $[17,18]$ clearly show that the size and shape of catalyst particle do not make any impact on deciding the structure of grown CNTs. In this context, a comprehensive study is presented in this report on temperature increasing rate of CVD and its influence on the role of catalyst as well as on the structural properties of CNTs. 


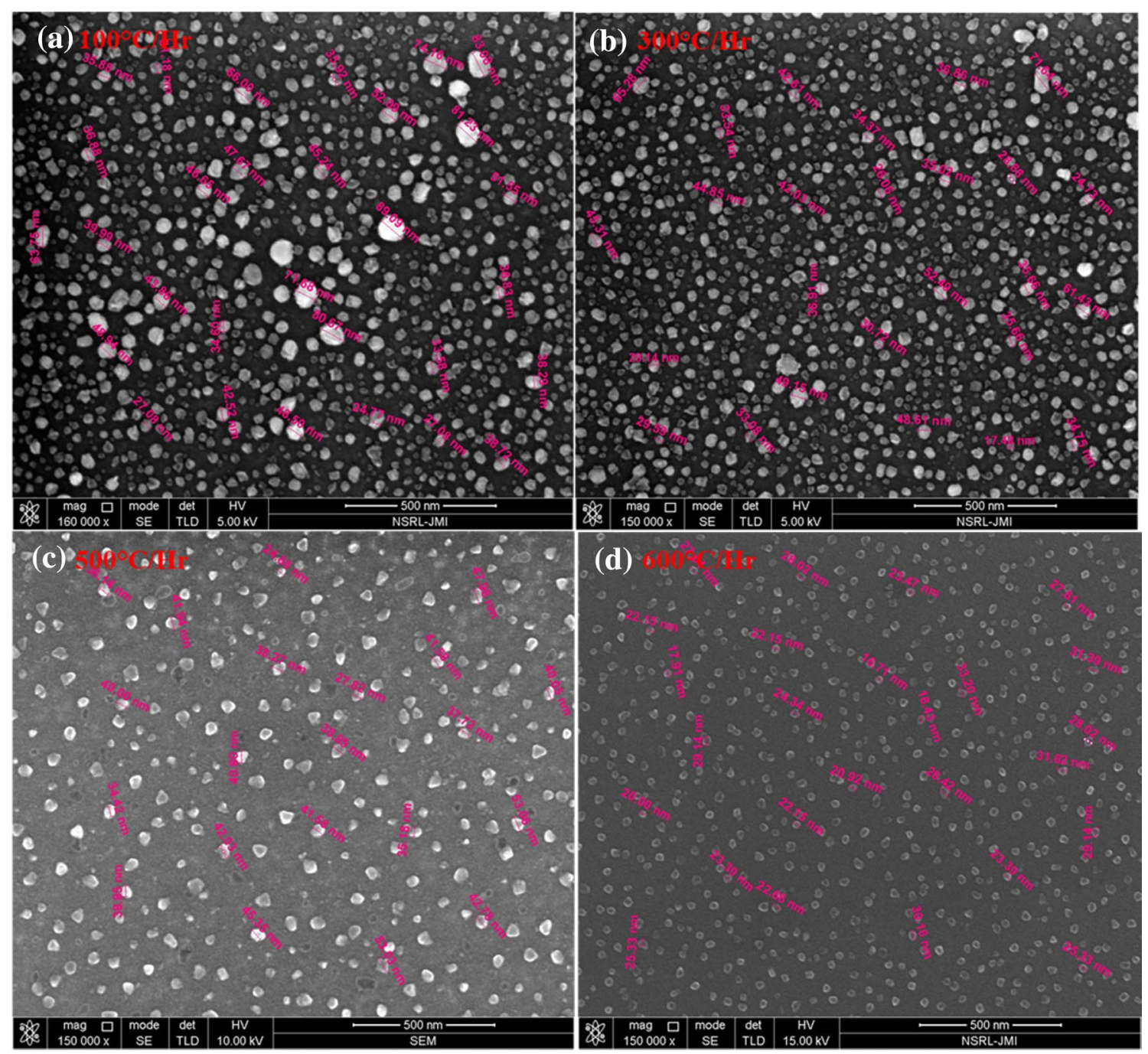

Fig. 1 Figure shows the catalyst particles prior to CNTs growth at different temperature increasing rate, a $100{ }^{\circ} \mathrm{C} / \mathrm{h}, \mathbf{b} 300{ }^{\circ} \mathrm{C} / \mathrm{h}, \mathbf{c} 500{ }^{\circ} \mathrm{C} / \mathrm{h}$ and d $600{ }^{\circ} \mathrm{C} / \mathrm{h}$

Fig. 2 XRD diffractogram for catalyst particles prior to grown CNTs with different temperature increasing rate, i.e., $100{ }^{\circ} \mathrm{C} / \mathrm{h}$ (red line), $300{ }^{\circ} \mathrm{C} / \mathrm{h}$ (black line), $500{ }^{\circ} \mathrm{C} / \mathrm{h}$ (green line) and $600^{\circ} \mathrm{C} / \mathrm{h}$ (blue line)

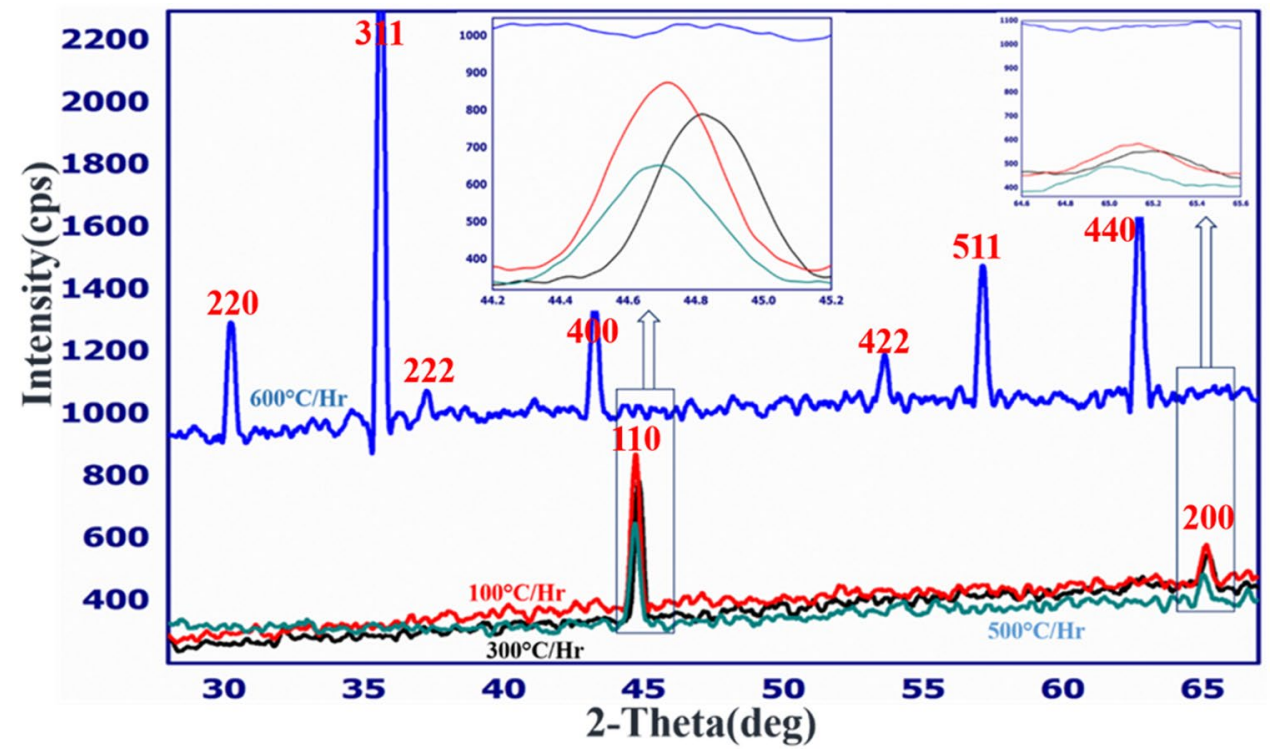


Processing parameters: All elements (Normalized) Number of iterations $=\mathbf{3}$

(a)

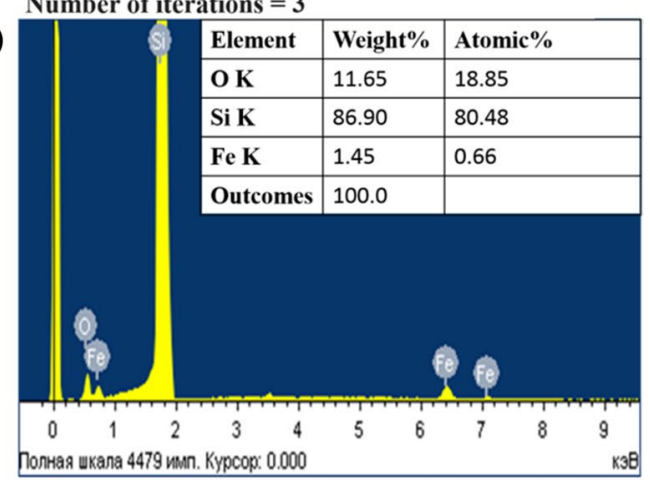

(b)

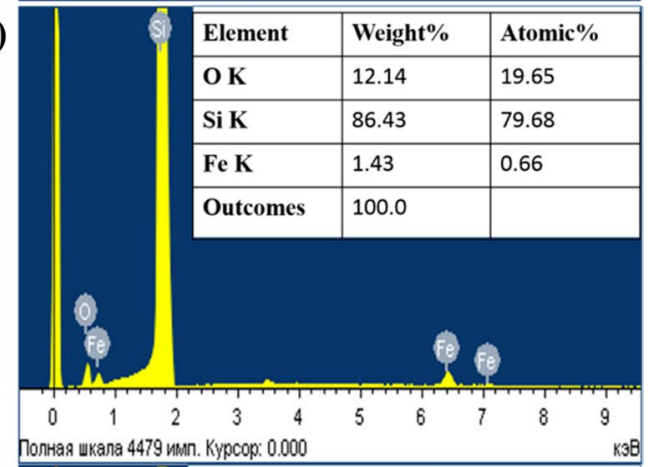

(c)

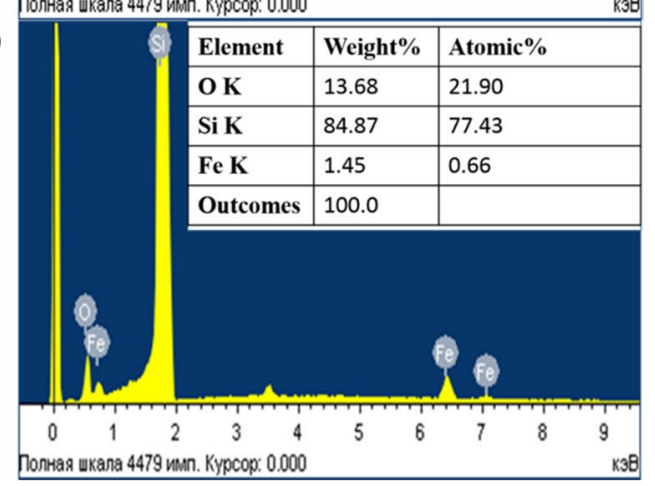

Fig. 3 Figure shows EDX analysis for iron catalyst treated with a $100{ }^{\circ} \mathrm{C} / \mathrm{h}$, b $500{ }^{\circ} \mathrm{C} / \mathrm{h}$ and c $600^{\circ} \mathrm{C} / \mathrm{h}$

\section{Experiment}

CNTs growth was carried on a $1 \mathrm{~cm} \times 1 \mathrm{~cm}$ silicon $(\mathrm{Si})$ substrate. For this, Si substrate was first cleaned by $5 \mathrm{~min}$ ultrasonication in IPA followed by 10 min oxygen plasma treatment using Plasma treatment System (Dinear, Germany). A $4 \mathrm{~nm}$ thin layer of iron is deposited on cleaned Si substrate using RF Sputtering system. In the next step, the prepared sample was loaded inside a horizontal reactor CVD system and then heated from room temperature to $775^{\circ} \mathrm{C}$ in the presence of $60 \mathrm{sccm}$ continuous flow of $\mathrm{Ar}$ gas at $100{ }^{\circ} \mathrm{C} / \mathrm{h}$ temperature increasing rate. When furnace temperature reached $775{ }^{\circ} \mathrm{C}$, carbon source gas $\mathrm{C}_{2} \mathrm{H}_{2}$ was allowed for $10 \mathrm{~min}$ to flow in the furnace. For cooling, furnace was turned off while Ar flow continued till the furnace temperature comes down to room temperature. Sample was then unloaded for investigation. Same experiment was repeated for $300{ }^{\circ} \mathrm{C} / \mathrm{h}, 500{ }^{\circ} \mathrm{C} / \mathrm{h}$ and $600{ }^{\circ} \mathrm{C} / \mathrm{s}$ temperature increasing rate while keeping other parameters constant. All experiments are conducted at atmospheric pressure.

Samples were characterized by microscopic as well as spectroscopic techniques to study various effects of temperature increasing rate on growth mechanism of CNTs. Morphology studies of grown samples were done by Scanning Electron Microscope (FEI, Nova Nano Sem 450), and HRTEM (FEI, Technai $\mathrm{G}^{2} 30 \mathrm{~S}$ Twin), whereas microRaman spectrometer with $488 \mathrm{~nm} \mathrm{Ar}^{+}$laser (LabRAM HR800, JY) and XRD (Rigaku) were used for structural analysis.

\section{Result and discussion}

It is well known fact that when we heat up the thin catalyst film deposited on a wafer, it usually breaks up into nanosize catalyst particles $[19,20]$. To verify the size and shape of catalyst particles, the individual sample was heated from room temperature to $775^{\circ} \mathrm{C}$ with different temperature increasing rate $\left(100,300,500\right.$ and $\left.600{ }^{\circ} \mathrm{C} / \mathrm{h}\right)$ followed by cooling down the furnace to room temperature. These samples were investigated by FESEM (see Fig. 1) after unloading from the CVD. The diameter distribution range of catalyst particles from 40-90, 30-80, $30-60$ and $20-50 \mathrm{~nm}$ with respect to $100,300,500$ and $600{ }^{\circ} \mathrm{C} / \mathrm{h}$ was observed . Further investigation of structural quality of iron catalyst particles was made by HRTEM and XRD. It is found in XRD spectra that the prepared sample with $100{ }^{\circ} \mathrm{C} / \mathrm{h}$ has the highest crystallinity as compared to others (see Fig. 2). It has only two peaks, one at $45^{\circ}$ and another at $65^{\circ}$, that represent the $\{110\}$ and $\{200\}$ planes of iron crystal lattice [21]. As we increase the heating rate of CVD system from 100 to $300{ }^{\circ} \mathrm{C} / \mathrm{h}$ and $500{ }^{\circ} \mathrm{C} / \mathrm{h}$ consecutively, the peak intensity of both decreases. It means that crystallinity of the respective samples decreases. Further increase in the temperature increasing rate to $600{ }^{\circ} \mathrm{C} / \mathrm{h}$ led to the disappearance of both the peaks. Instead, sample displayed multiple peaks $\left(30^{\circ}, 35^{\circ}, 37^{\circ}, 44^{\circ}, 54^{\circ}, 58^{\circ}\right.$ and $63^{\circ}$ ) which are exactly same as that usually present for iron oxides. These peaks represent $\{220\},\{311\},\{222\}$, $\{400\},\{422\},\{511\}$ and $\{440\}$ planes of iron oxides [22]. It is well-known fact that to make oxides of any metal, defects and disorders on the top surface of metal works as a building block [23] because these defects and disorders cause the increase in the reactivity of metal surface [24]. It means that if the top surface of the metal is more defective, then more oxygen molecules can attach 
Fig. 4 HR-TEM images of catalyst particles with different temperature increasing rate, a $100{ }^{\circ} \mathrm{C} / \mathrm{h}$, b $300{ }^{\circ} \mathrm{C} / \mathrm{h}, \mathbf{c}$ $500{ }^{\circ} \mathrm{C} / \mathrm{h}$ and $\mathrm{d} 600^{\circ} \mathrm{C} / \mathrm{h}$
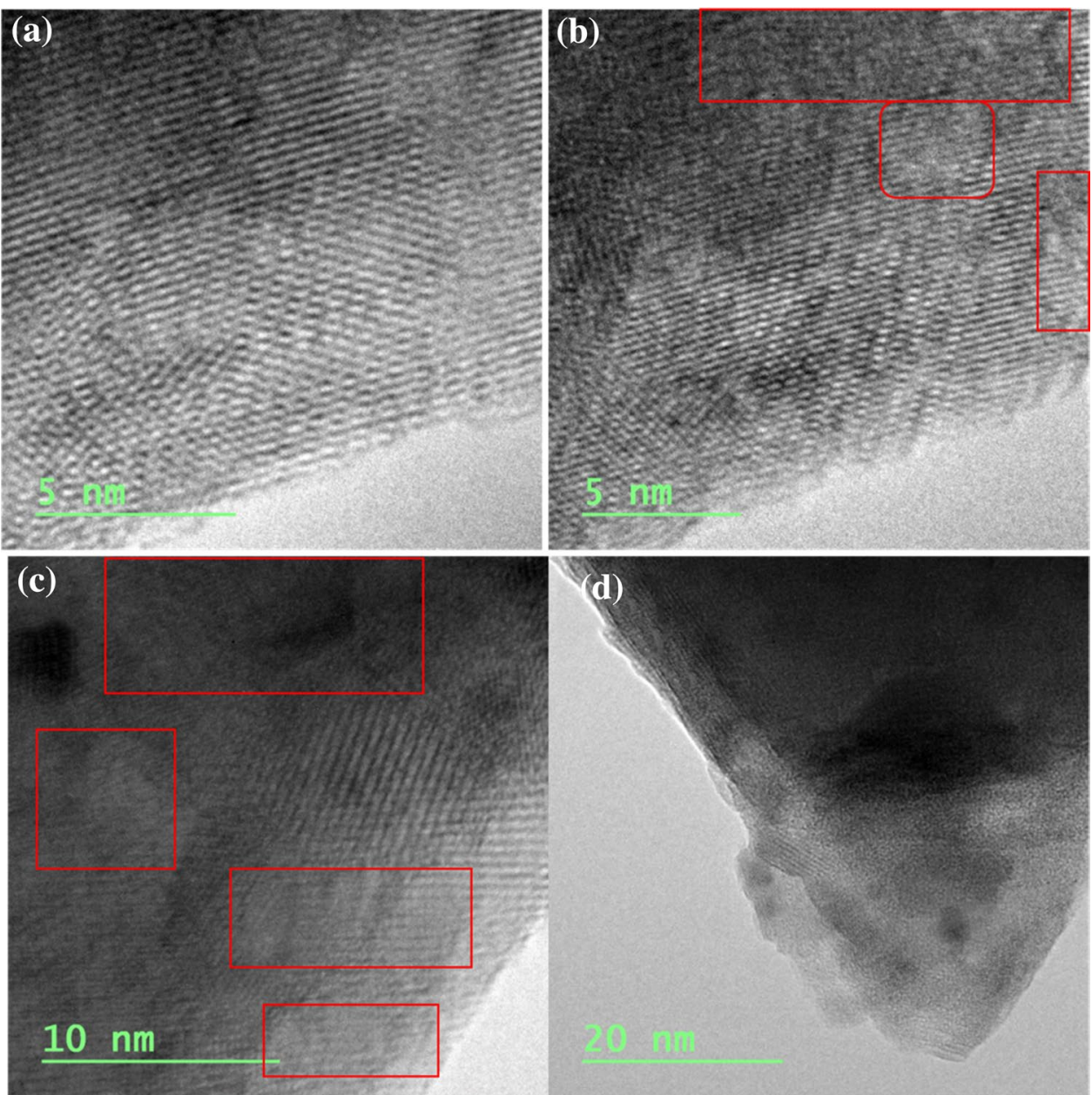

to it. To verify this assumption about oxygen molecules attachment, EDX (INCA X-act, Oxford instruments) analysis was performed on the sample prepared at temperature increasing rate of 100,500 and $600{ }^{\circ} \mathrm{C} / \mathrm{h}$ (see Fig. 3). It shows that the oxygen quantity increases with rise in temperature increase rate and, therefore, confirms that defect density increases with temperature increasing rate. Figure 4 shows the HRTEM images for iron catalyst particles, in which it is observed that sample heated with $100{ }^{\circ} \mathrm{C} / \mathrm{h}$ has less defects and less disorders among all samples. These disordered sites increase when temperature increasing rate increases to $300{ }^{\circ} \mathrm{C} / \mathrm{h}$ (see within red portion of Fig. 4). When we further increase the temperature increasing rate to $500{ }^{\circ} \mathrm{C} / \mathrm{h}$, disorder density on top of the surface becomes larger than previous case. Interestingly, at temperature increasing rate $600{ }^{\circ} \mathrm{C} / \mathrm{h}$, the top surface of the catalyst particle has much disorders as compared to the previous three cases, because grain boundaries are almost invisible or completely covered by oxygen molecules, as in the HRTEM image of Fig. 4d.

For synthesis of CNTs, sample is heated from room temperature to $775^{\circ} \mathrm{C}$ in the presence of argon gas, and at required growth temperature achieved, hydrocarbon sources are supplied inside the chamber. We supplied argon gas to prevent the catalyst from oxidization [25]. Since iron oxides do not benefit CNTs growth, therefore, precaution was also taken to avoid any deposition of oxides on the metal surface. Even if there is any oxide layer deposited on the iron catalyst surface before loading in CVD chamber, it gets cleaned during heating process in the presence of argon atmosphere. At the time of investigation of catalyst particles by HRSEM, HRTEM and EDX, we unloaded the samples subjected to different temperature increasing rates in argon atmosphere without providing hydrocarbon source. After unloading for investigation, these catalyst particles come in open atmosphere and, hence, become oxidized due to oxygen attachment on the defective sites on the top surface of the iron catalyst particles.

In summary, many lattice planes are present in sample prepared at $600{ }^{\circ} \mathrm{C} / \mathrm{h}$ temperature increasing rate, making it lesser crystalline with more disorders on the top surface of catalyst. 
Fig. 5 Figure shows the HRTEM micrograph for CNTs growth at a $100{ }^{\circ} \mathrm{C} / \mathrm{h}$, b $300{ }^{\circ} \mathrm{C} / \mathrm{h}$, c $500{ }^{\circ} \mathrm{C} / \mathrm{h}$ and $\mathbf{d}$ $600{ }^{\circ} \mathrm{C} / \mathrm{h}$ temperature increasing rate, respectively
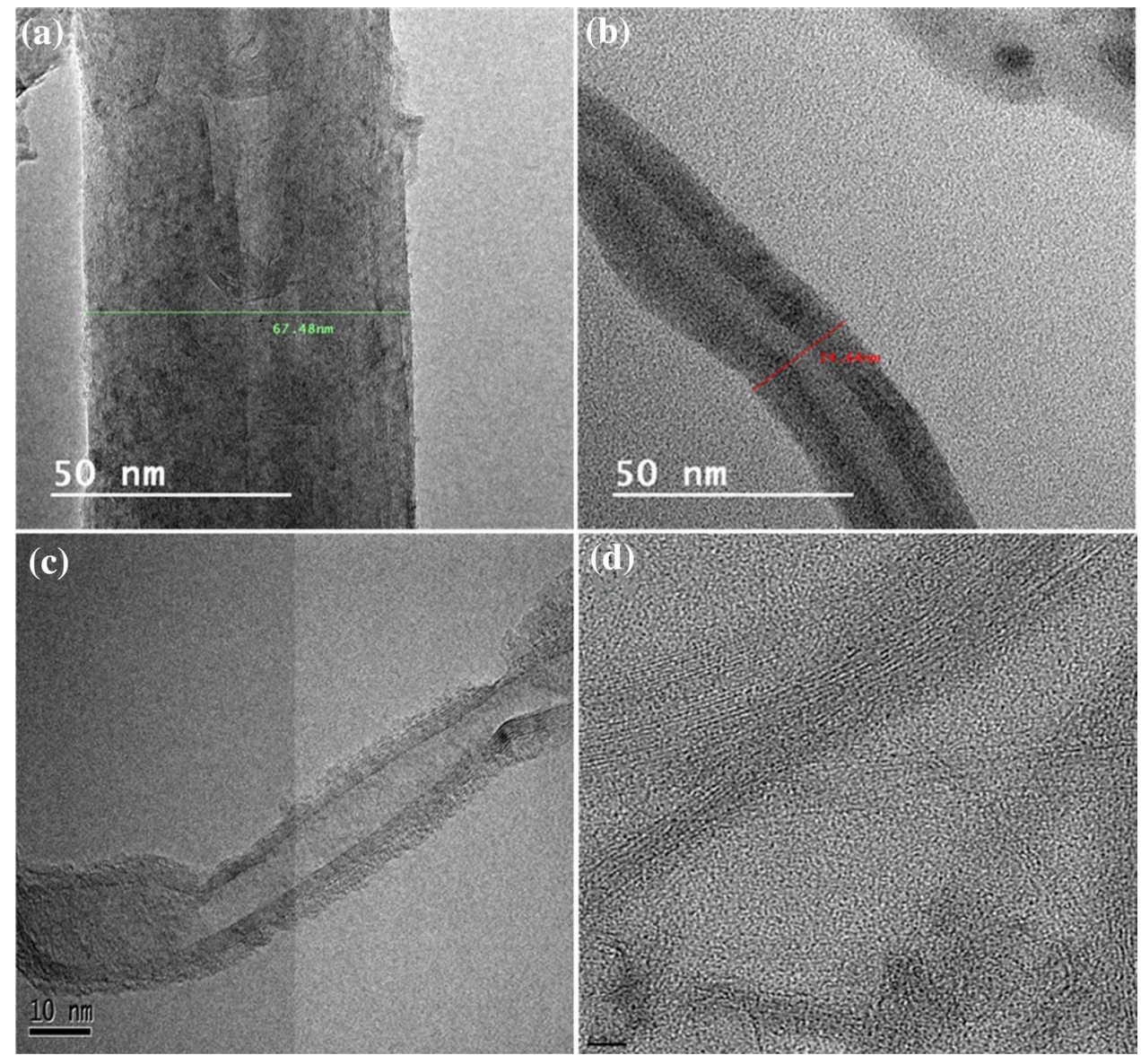

When hydrocarbon source is allowed to flow inside the CVD chamber then due to the decomposition of these hydrocarbons, formation of carbon atoms occurs. Firstly, these carbon atom attached to highly reactive disordered sites of the iron catalyst. In fact, the defect or disordered sites attached to carbon atoms provide a base to the CNTs for their growth. Figures 5a, 6a and 7a show the HRTEM, FESEM and Raman spectra of grown CNTs with temperature increasing rate $100{ }^{\circ} \mathrm{C} / \mathrm{h}$. It is observable from HRTEM image that CNTs have diameter $65 \mathrm{~nm}$ approximately (Fig. 5a). Grown CNTs having poor yield with shorter length are further shown in the FESEM image (Fig. 5a). Structural quality of grown CNTs was investigated by Raman Spectroscopy, where it is found that the grown CNTs have very strong peak of D-Band, vis-à-vis G-Band (Fig. 7a). The intensity ratio of D- to G-band $\left(I_{\mathrm{D}} / I_{\mathrm{G}}\right)$ of grown CNTs is found very large, i.e., 1.20, and it indicates the growth of poor quality CNTs. This poor quality of CNT growth can be due to the highly crystalline and less defect states in iron catalyst synthesis at $100{ }^{\circ} \mathrm{C} / \mathrm{h}$. This highly crystalline structure is clearly visible in XRD and HRTEM results. Due to high crystallinity of iron catalyst, the defects or disordered sites per unit area are very less. This results in the distant defective sites on the catalyst surface.
To initiate CNTs growth, the formation of a base of carbon atoms, either in the form of semi-buckyballs or graphene or some other manner, is desirable. After some duration, further carbon atoms are attached with it, and it takes the form of CNTs. For base formation, the required carbon atoms firstly attached to the defective sites of crystal lattice. If these defective sites of crystal structure exist far from each other, then carbon atoms also attach at distance, leading to less minimum requirement of carbon atoms for base formation of CNTs or initiation of CNTs growth with a wide gap between each other. As a result, grown CNTs also have larger diameter, and the presence of less defective sites on the crystal lattice, effectively reduces the nucleation sites for CNTs growth leading to less yield of CNTs. When the production of carbon atoms is too much as compared to the requirement, it increases the number of walls in grown CNTs. This is another cause for large diameter of grown CNTs. In addition, extra carbon atoms will deposit on the outer surface of CNTs wall in amorphous form; as a result, the defects in grown CNTs also increase. It may be the reason for larger $I_{\mathrm{D}} / I_{\mathrm{G}}$ in Raman spectra of grown CNTs.

While temperature increasing rate of CVD system increases to $300^{\circ} \mathrm{C} / \mathrm{h}$, the diameter of grown CNTs decreases rapidly to around $24 \mathrm{~nm}$ (Fig. 5b). Figure 6b shows its 
Fig. 6 Figure shows the FESEM images for CNTs growth at temperature increasing rate at a $100{ }^{\circ} \mathrm{C} / \mathrm{h}, \mathbf{b} 300^{\circ} \mathrm{C} / \mathrm{h}$, c $500{ }^{\circ} \mathrm{C} / \mathrm{h}$ and d $600{ }^{\circ} \mathrm{C} / \mathrm{h}$, respectively

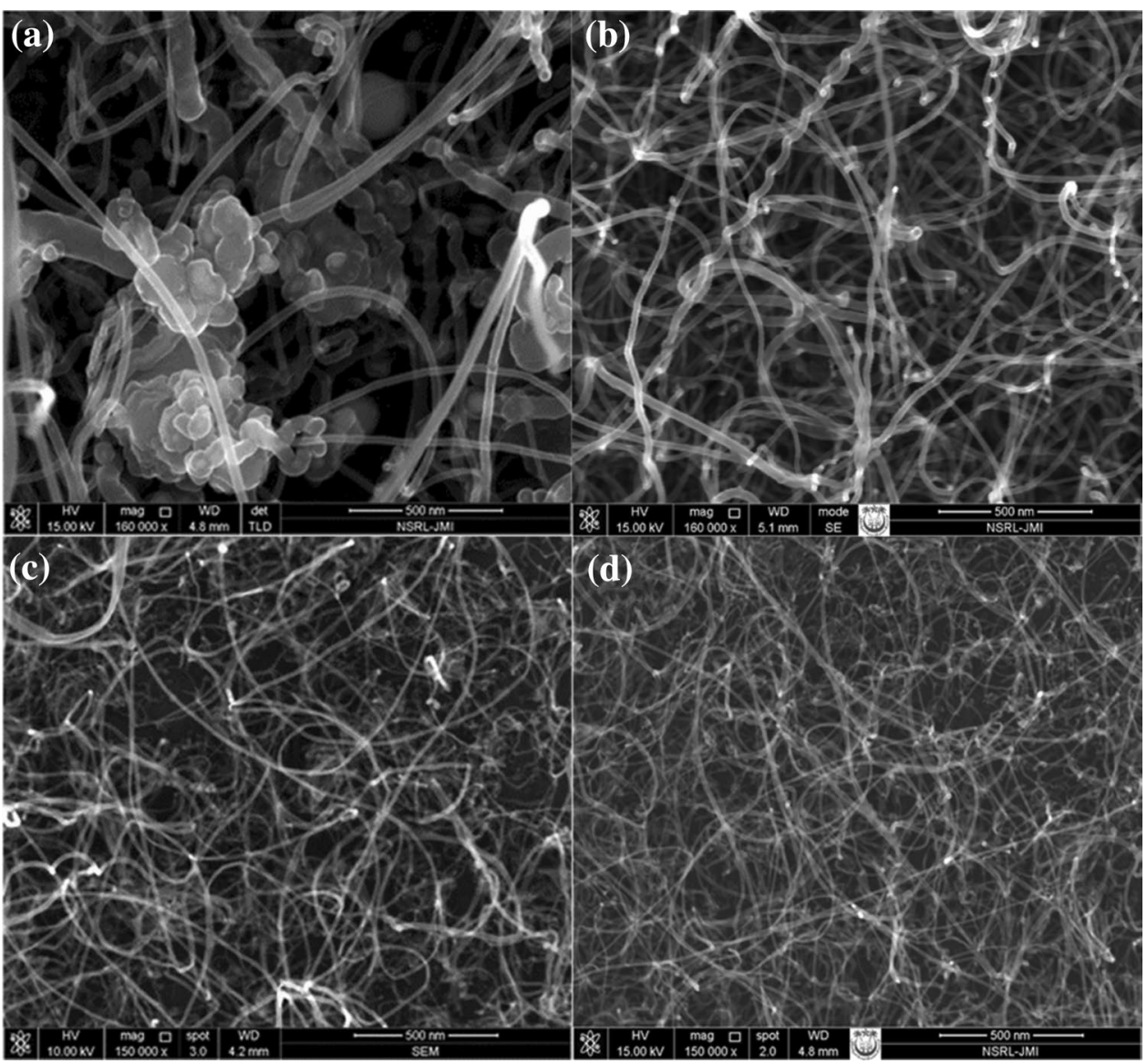

morphological study by FESEM investigation, where dense horizontal network with improvement in structural quality of CNTs is clearly observed. It led to sharp reduction in $I_{\mathrm{D}} / I_{\mathrm{G}}$ ratio of Raman spectra (see Fig. 7b). Surprising changes in morphological and structural quality also occurred due to the decrease in crystallinity of iron catalyst particles (also shown in XRD image in Fig. 2). Due to reduction in crystallinity in crystal lattice, defective sites or disorders on the top surface of catalyst particle increase while making the distance between defective sites to decrease and make carbon atoms closer for initiation of CNTs growth. As a result, it reduces the diameter of semi-bulkyball or area of graphene sheet formed on base, leading to decrease in the diameter of grown CNTs. It turns out to be an important factor that increment in nucleation sites causes increase in the yield of grown CNTs per catalyst and, therefore, the total yield. Again, the increment in yield leads to increase in the requirement of carbon atoms for CNTs growth. This maintains the balance between the production of carbon atom and its requirement. In fact, less amorphous carbon is deposited on outer wall of CNTs causing improvement of structural quality of CNTs. Decrease in $I_{\mathrm{D}} / I_{\mathrm{G}}$ ratio confirms the improvement in structural quality of CNTs.
Tuning of carbon atoms may be used as a tool to help in decreasing the number of walls and hence diameter. To verify our proposed growth mechanism, we increase the temperature increasing rate from 300 to $500{ }^{\circ} \mathrm{C} / \mathrm{h}$. In that case, catalyst particles become enriched with disorders present on the top surface of catalyst particles. Therefore, better results were found as expected. It is observed that diameter of CNTs decreases to around $10 \mathrm{~nm}$ (HRTEM image of Fig. 5c). From FESEM image of Fig. 6c, it is observed that yield of CNTs also increases as compared to growth of CNTs with 100 and $300{ }^{\circ} \mathrm{C} / \mathrm{h}$ temperature increasing rate. An enhancement in structural quality also observed in Raman spectra (Fig. 7c).

Further, improved results were obtained while repeating the same experiment with temperature increasing rate of $600{ }^{\circ} \mathrm{C} / \mathrm{h}$, where SWNTs less than $2 \mathrm{~nm}$ diameter were grown with good structural quality as well as yields (see Figs. 5d, 6d and 7d).

It is clearly observed in FESEM image of Fig. 1 that the particle size of catalyst is changed, but this change is small as compared to the change in the diameter of CNTs. The maximum diameter of the catalyst particle observed is $90 \mathrm{~nm}$ (Fig. 1a) for the catalyst film treated at $100^{\circ} \mathrm{C} / \mathrm{h}$, whereas the minimum diameter of $20 \mathrm{~nm}$ (see Fig. 1d) was found for the catalyst prepared at $600{ }^{\circ} \mathrm{C} / \mathrm{h}$; so the difference 

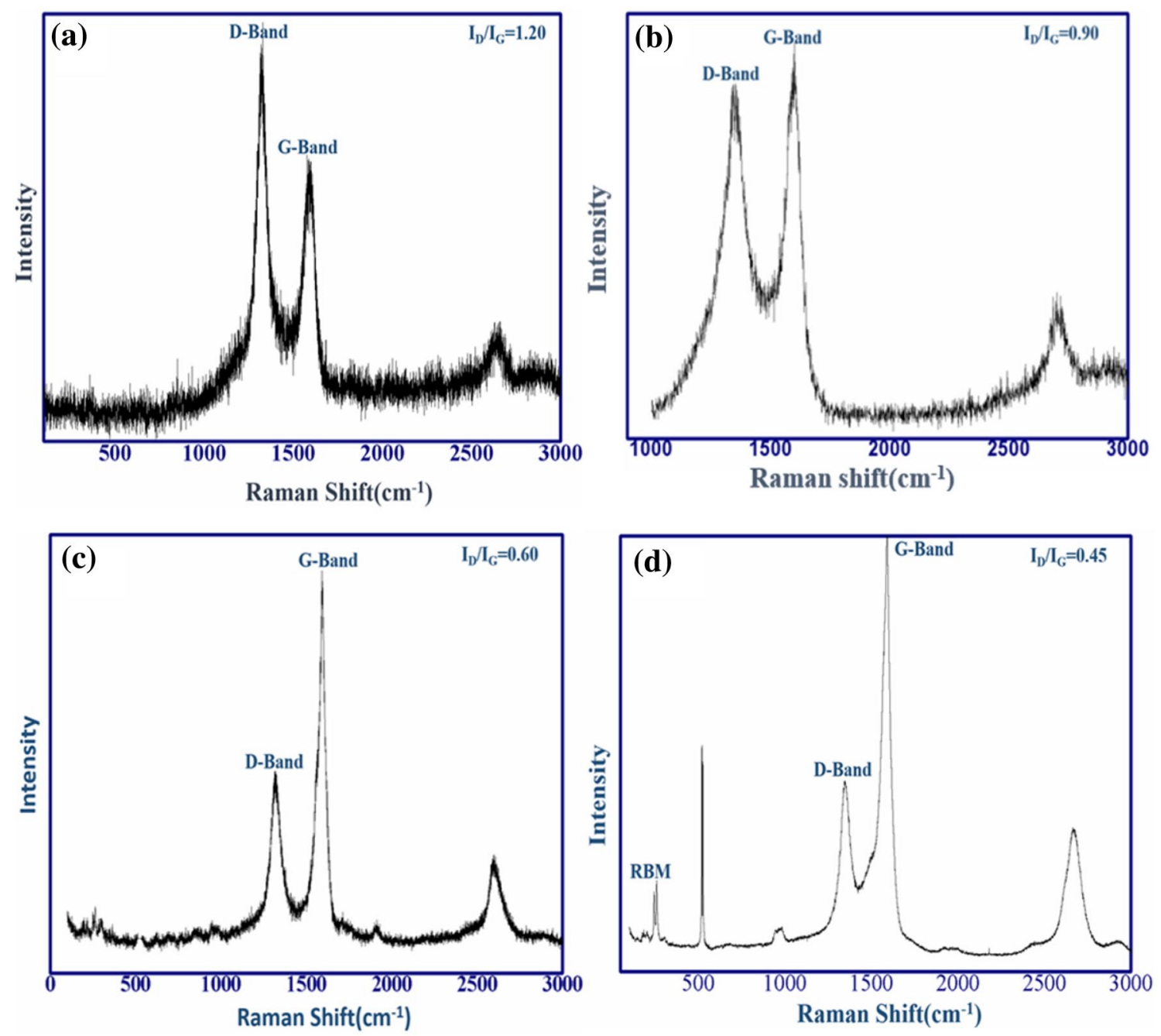

Fig. 7 Figure shows the Raman spectra for CNTs growth at temperature increasing rate at a $100{ }^{\circ} \mathrm{C} / \mathrm{h}, \mathbf{b} 300{ }^{\circ} \mathrm{C} / \mathrm{h}, \mathbf{c} 500{ }^{\circ} \mathrm{C} / \mathrm{h}$ and d $600{ }^{\circ} \mathrm{C} / \mathrm{h}$, respectively

between minimum and maximum diameter of catalyst particle is only 4.5 times. For average diameter is concerned, it was observed that the average diameter of grown CNTs at $100{ }^{\circ} \mathrm{C} / \mathrm{h}$ is around $70 \mathrm{~nm}$ while average diameter of grown CNTs at $600{ }^{\circ} \mathrm{C} / \mathrm{h}$ is approximately $2 \mathrm{~nm}$. So, difference in average diameter of CNTs for both cases is around 35 times. In addition to this, catalyst particles having diameter of $20 \mathrm{~nm}$ produced CNTs with diameter of $2 \mathrm{~nm}$ only. So, if diameter of CNTs is controlled by diameter of catalyst particle then grown CNTs must also have same range of diameter, and that did not happen in the present case. According to the existing growth mechanism theory [17], a carbon atom is first attached to the boundary of the catalyst particle and then more carbon atoms join them, resulting in a graphene cap on the catalyst particle. This graphene cap float over the catalyst particle with the boundary atoms of the graphene cap remains attached to the catalyst particle. Later on, more carbon atoms attached to the boundary atoms of graphene which causes the upward motion of graphene cap and therefore the formation of a cylindrical wall. So, in this case when carbon atoms attached on the boundary of catalyst particles then diameter of CNTs can be approximated same as diameter of catalyst. The researchers concluded that the effective attachment of carbon atom and, thereby, the formation of graphene network crucially depend on monoatomic steps at the boundary of the catalyst particle.

The authors also proposed that small nanoparticles are essential for the growth of SWNTs. Small catalyst particles with the diameter of 1-2 $\mathrm{nm}$ have sharp edges and, therefore, have high catalytic activity which causes the formation of high-strain SWNTs. However, as the catalyst size increases, the sharpness at the edges decreases resulting in lesser catalyst activity. Therefore, catalyst particles with bigger diameter of around 5-20 nm produce less strains on MWNTs. In addition, catalyst particles with even higher diameter (i.e., 
$100 \mathrm{~nm}$ ) possess no sharp steps and, therefore, they are unable to form CNTs.

The standard growth mechanism may be true for small size catalyst particles (1-2 $\mathrm{nm}$ ) but in case of large size catalyst particles some other factors can influence the growth of CNTs. So, in this manuscript, the synthesis of SWNTs with $20 \mathrm{~nm}$ diameter catalyst particles and the involved CNT growth mechanism is presented. It means diameter of grown CNTs is independent from the size of catalyst particle, which is in contrary to the views reported by the earlier researchers that the diameter of CNTs is highly dependent on the size of the catalyst particle. This new observation was investigated in the present manuscript with suitable explanations.

\section{Conclusion}

Temperature increasing rate plays a crucial role in growth mechanism of CNTs, and proper experimentation was conducted to see its influence on the diameter, yield and structural quality of grown CNTs. Successful observations were made in these fronts simply by tuning the temperature increasing rate. At lesser temperature increasing rate, MWNTs are synthesized, whereas at higher temperature increasing rate, SWNTs are successfully achieved. We also conclude that for the growth of best quality CNTs with lesser diameter, the temperature increasing rate should be as much as possible. It was proved by the present study that the size of the catalyst does not play any role in deciding the diameter of CNTs. In support of this observation, experimental results demonstrate that diameter of CNT is much lesser than the diameter of the catalyst. The disorders present on the top surface of catalyst particles are actually responsible and the decisive factor for the diameter of grown CNTs.

Open Access This article is distributed under the terms of the Creative Commons Attribution 4.0 International License (http://creativeco mmons.org/licenses/by/4.0/), which permits unrestricted use, distribution, and reproduction in any medium, provided you give appropriate credit to the original author(s) and the source, provide a link to the Creative Commons license, and indicate if changes were made.

\section{References}

1. Yang, N., Pang, D.W., Jiang, X.: Carbon Nanoparticles and Nanostructures. Springer International Publishing, Switzerland (2016)

2. Narayanan, K.B., Han, S.S.: Helical plant viral nanoparticlesbioinspired synthesis of nanomaterials and nanostructures. Bioinspir. Biomim. 12, 031001 (2017)

3. Sharma, P., Gupta, N.: Threshold voltage modeling on nanocrystalline silicon thin-film transistors. J. Electron Devices 19, 1608 (2014)

4. Zhang, T., Mubeen, S., Myung, N.V., Deshusses, M.A.: Recent progress in carbon nanotube-based gas sensors. Nanotechnology 19, 332001 (2008)
5. Choi, W.B., Chung, D.S., Kang, J.H., Kim, H.Y., Jin, Y.W., Han, I.T., Lee, Y.H., Jung, J.E., Lee, N.S., Park, G.S., Kim, J.M.: Fully sealed, high-brightness carbon-nanotube field-emission display. Appl. Phys. Lett. 75, 3129 (1999)

6. Yanez H., J.E., Wang, Z., Lege, S., Obst, M., Roehler, S., Burkhardt, C.J., Zwiener, C.: Application and characterization of electroactive membranes based on carbon nanotubes and zerovalent iron nanoparticles. Water Res 108, 78 (2017)

7. Tripathi, N., Islam, S.S.: A new approach for orientation-controlled growth of CNTs: an in-depth analysis on the role of oxygen plasma treatment to catalyst. Appl. Nanosci. 7, 125 (2017)

8. Lim, Y.D., Hu, L., Avramchuck, A.V., Grapov, D., Tay, B.K., Aditya, S., Miao, J., Labunov, V.: Temperature-dependent selective growth of carbon nanotubes in $\mathrm{Si} / \mathrm{SiO}_{2}$ structures for field emitter array applications. Mater. Res. Bull. 95, 129 (2017)

9. Tripathi, N., Mishra, P., Harsh, H., Islam, S.S.: Fine-tuning control on CNT diameter distribution, length and density using thermal CVD growth at atmospheric pressure: an in-depth analysis on the role of flow rate and flow duration of acetylene $\left(\mathrm{C}_{2} \mathrm{H}_{2}\right)$ gas. Appl. Nanosci. 5, 5 (2015)

10. Sivakumar, V.M., Mohamed, A.R., Abdullah, A.Z., Chai, S.P.: Role of reaction and factors of carbon nanotubes growth in chemical vapour decomposition process using methane-a highlight. J. Nanomater. 2010, 1 (2010)

11. Tripathi, N., Mishra, P., Joshi, B., Islam, S.S.: Precise control over physical characteristics of carbon nanotubes by differential variation of argon flow rate during chemical vapor deposition processing: a systematic study on growth kinetics. Mater. Sci. Semicond. Process. 35, 207 (2015)

12. Pham, Q.N., Larkin, L.S., Lisboa, C.C., Saltonstall, C.B., Qiu, L., Schuler, J.D., Rupert, T.J., Norris, Pamela M.: Effect of growth temperature on the synthesis of carbon nanotube arrays and amorphous carbon for thermal applications. Phys. Status Solidi A 1600852, 1 (2017)

13. Lee, C.J., Park, J., Huh, Y., Lee, J.Y.: Temperature effect on the growth of carbon nanotubes using thermal chemical vapor deposition. Chem. Phys. Lett. 343, 33 (2001)

14. Tripathi, N., Pavelyev, V., Islam, S.S.: Synthesis of carbon nanotubes using green plant extract as catalyst: unconventional concept and its realization. Appl. Nanosci. 7, 557 (2017)

15. Tripathi, N., Mishra, P., Joshi, B., Islam, S.S.: A systematic study on growth of CNTs with liquid chemical salts as catalysts: a fine control on orientation of CNTs. Adv. Sci. Lett. 20, 1612 (2014)

16. Morjan, R.E., Nerushev, O.A., Sveningsson, M., Rohmund, F., Falk, L.K.L., Campbell, E.E.B.: Growth of carbon nanotubes from C60. Appl. Phys. A 78, 253 (2004)

17. Kumar, M., Ando, Y.: Controlling the diameter distribution of carbon nanotubes grown from camphor on a zeolite support. Carbon 43, 533 (2005)

18. Fan, S., Chapline, M., Frankline, N., Tombler, T., Cassel, A.M., Dai, H.: Self-oriented regular arrays of carbon nanotubes and their field emission properties. Science 283, 512 (1999)

19. Jourdain, V., Bichara, C.: Current understanding of the growth of carbon nanotubes in catalytic chemical vapour deposition. Carbon 58, 2 (2013)

20. Gao, J.S., Umeda, K., Uchino, K., Nakashima, H.: Plasma breaking of thin films into nano-sized catalysts for carbon nanotube synthesis. Mater. Sci. Eng. A 352, 308 (2003)

21. Dadashi, S., Poursalehi, R., Delavari, H.: Structural and optical properties of pure iron and iron oxide nanoparticles prepared via pulsed Nd:YAG laser ablation in liquid. Procedia Mater. Sci. 11, 722 (2015)

22. Balasubramanian, C., Joseph, B., Orpe, P.B., Saini, N.L., Mukherjee, S., Kocurek, K.D., Stanek, J., Gioacchino, D.D., Marcelli, A.: Defective iron-oxide nanoparticles synthesised by 
high temperature plasma processing: a magnetic characterisation versus temperature. Nanotechnology 27, 445701 (2016)

23. Parkinson, G.S.: Iron oxide surfaces. Surf. Sci. Rep. 71, 272 (2016)

24. Šepelák, V., Colin, S.B., Caër, G.L.: Transformations in oxides induced by high-energy ball-milling. Dalton Trans. 41, 11927 (2012)
25. Khorrami, S.A., Lotf, R.: Influence of carrier gas flow rate on carbon nanotubes growth by TCVD with $\mathrm{Cu}$ catalyst. J. Saudi Chem. Soc. 20, 432 (2016)

Publisher's Note Springer Nature remains neutral with regard to jurisdictional claims in published maps and institutional affiliations. 